Gefässchirurgie 2019· 24 (Suppl 1):S32-S39 https://doi.org/10.1007/s00772-018-0490-9 Published online: 24 January 2019

(c) The Author(s) 2018

CrossMark

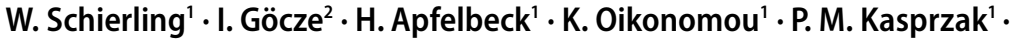
K. Pfister ${ }^{1}$

${ }^{1}$ Abteilung für Gefäßchirurgie, Universitätsklinikum Regensburg, Regensburg, Germany

${ }^{2}$ Klinik für Chirurgie und Chirurgische Intensivmedizin, Universitätsklinikum Regensburg, Regensburg, Germany

\title{
Bedside ultrasound after aortic surgery
}

\section{Rapid detection of vascular and organ complications}

high-risk patients who would have been excluded from open surgery in the past nowadays receive treatment. The risk of potential perioperative complications is increasing as a consequence, as is inhospital mortality $(2.0 \%$ in patients aged over 80 years compared to $0.7 \%$ among those under 80 years after EVAR, versus $14.5 \%$ and $3.1 \%$, respectively, after open surgery for symptom-free abdominal aortic aneurysms, AAA [14]). Adequate perioperative management is thus of paramount importance. Particularly in the case of early complications, rapid and targeted diagnostic measures are necessary to prevent long-term damage and reduce mortality.

Early and late complications have to be expected after both open and endovascular aortic surgery. According to 2016 data from the German Institute for Vascular Medicine Healthcare Research (DIGG, Deutsches Institut für Gefäßmedizinische Gesundheitsforschung) of the German Society for Vascular Surgery and Vascular Medicine (DDG, Deutsche Gesellschaft für Gefäßchirurgie und Gefäßmedizin), the morbidity rate following endovascular aortic repair (EVAR) of symptom-free aortic aneurysms is $11.2 \%$, compared to $29 \%$ after open surgery; the mortality is given as $1.0 \%$ and $4.1 \%$, respectively [14]. An increasing number of older and

The German version of this article can be found under https://doi.org/10.1007/s00772018-0478-5.

\section{Early complications after aortic interventions}

Early complications include vascular access complications, such as acute vessel occlusion, stenosis, dissection, bleeding, hematoma or false aneurysm. Depending on the complexity of the surgical intervention, iliac leg occlusion/ thrombosis or occlusions, thromboses, and dissections of renal and visceral arteries are possible. Embolization can lead to partial or complete organ infarction, intestinal ischemia and cerebral or acute peripheral ischemia. Additionally, cardiopulmonary and cerebrovascular complications, acute worsening of renal function or acute kidney failure, retroperitoneal bleeding and rectal sheath hematomas, deep vein thromboses in the legs and pulmonary embolisms, as well as spinal ischemia can occur [6]. The frequencies of vessel and organ complications after EVAR and open surgery are presented in • Table 1.

Approximately $25 \%$ of patients with acute type B aortic dissection present with a complicated dissection. Such a situation is defined by the presence of malperfusion syndrome or hemodynamic instability [2]. Malperfusion syndrome is described to occur at a frequency of approximately $10 \%$ in acute type B dissections. Clinical symptoms are often initially unclear [2]. Computed tomography angiography (CTA) can reveal a true lumen collapse, intima flaps, or a delayed to absent contrast enhancement of the kidneys [2] but
Table 1 Vessel and organ complications after endovascular aortic repair (EVAR) and open surgery $[6,9,10]$

\begin{tabular}{lll} 
& EVAR (\%) & Open surgery (\%) \\
\hline Vessel complications & $3.0-5.1$ & 1.1 \\
\hline Bleeding/hematoma & 5.7 & 5.9 \\
\hline Thromboembolism & 7.7 & 1.8 \\
\hline Kidney failure & $3.0-6.7$ & 4.2 \\
\hline Ischemic complications & $3-10$ & -
\end{tabular}



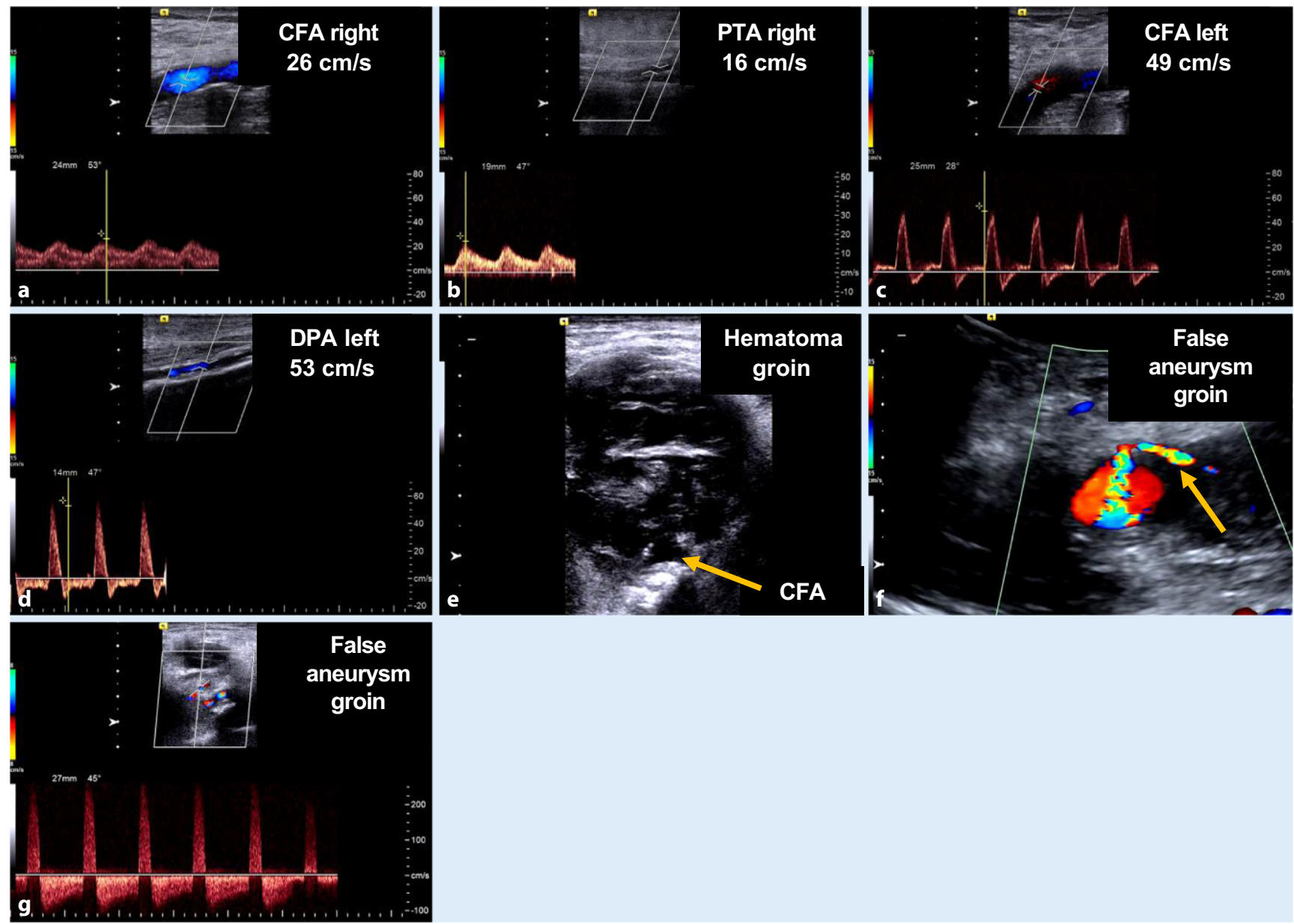

Fig. 1 ॥ Vascular (access) complications. a, b Flattened, monophasic flow profile with reduced flow speed in the common femoral artery (CFA) and posterior tibial artery (PTA) on the right due to an upstream occlusion of the iliacleg. c, d In comparison, normal biphasic and triphasic flow dynamics in the left-sided CFA and dorsalis pedis artery (DPA). e Large hematoma in the groin area (CFA marked by an arrow). $\mathbf{f}, \mathbf{g}$ False aneurysm (arrow) from the CFA with typical aneurysm neck and to-and-fro flow

is not always unambiguous due to limitation of the results to generally just two phases (early and late phases).

\section{Diagnostic possibilities}

After complex aortic interventions, patients are nearly always treated in the intensive care unit (ICU). In the case of perioperative complications, further diagnostic assessment with CTA or magnetic resonance imaging (MRI) requires patient transportation, which not only consumes personnel resources but also constitutes a risk for critically ill patients. Moreover, exposure to contrast agents can further exacerbate pre-existing renal insufficiency.

Color duplex and contrast-enhanced ultrasound have several advantages in this respect: the ultrasound examination can be performed at the bedside in the ICU, can be repeated as often as required, is not stressful for the patients, and has no nephrotoxicity.

\section{1) Ultrasound can be used for bedside diagnostics}

Using illustrative examples, the following article presents the possibilities of bedside ultrasound for rapid diagnosis of vessel and organ complications after aortic interventions and in patients with aortic dissection.

\section{Technical requirements}

The use of B-mode and color duplex ultrasound is possible with almost all modern ultrasound systems. For this two transducers of different penetration depths are required (sector or linear type probes). Contrast-enhanced ultrasound functions with system-specific software, which is nowadays available in all highend systems of ultrasound manufacturers or can be retrofitted. Via a reduction in the acoustic power or so-called mechanical index (MI) of the transducer, the injected microbubbles of ultrasound contrast medium (SonoVue ${ }^{\circledR}$, Bracco Imaging Deutschland GmbH, Konstanz, Germany, https://imaging.bracco.com) are excited but not destroyed. The microbubbles remain intravascular (blood pool agent) and are expelled in exhaled breath. This image is displayed as echorich blood flow on a black background [12].

Severe anaphylactic or anaphylactoid reactions occur at a frequency of 
$1: 10,000$. The cause is presumed to be complement activation via an interaction of the microbubbles with macrophages or basophils. Patients are thus required to give informed consent in non-emergency situations. SonoVue ${ }^{\circledR}$ must not be used together with dobutamine or in patients with a contraindication to dobutamine. Caution is advised in coronary thrombosis patients. SonoVue ${ }^{\circledR}$ is contraindicated in patients aged under 18 years and those with a known right-to-left shunt, severe pulmonary hypertension, uncontrolled systemic hypertension, or acute respiratory distress syndrome, as well as in pregnant and breastfeeding women (see SonoVue ${ }^{\circledR}$ product information). According to the current European Federation of Societies for Ultrasound in Medicine and Biology (EFSUMB) guidelines from 2017, adequate experience and specialist user training is recommended for clinical use of contrast agent-enhanced ultrasound [15].

\section{Vascular access complications}

Color duplex ultrasound enables conclusions to be drawn regarding peripheral perfusion. This permits differentiation between acute vessel occlusion, vascular stenosis and dissection and thus between reduced or absent perfusion. The location and length of an existing occlusion/ stenosis can be identified. - Fig. 1a-d show examples of flow dynamics in the common femoral artery (CFA) and the posterior tibial artery (PTA)/dorsalis pedis artery (DPA) after EVAR in a leftright comparison. Right-sided vessels demonstrate a flattened monophasic flow profile with significantly reduced flow speed (- Fig. 1a, b) compared to the steep biphasic profile of vessels on the left (- Fig. 1c, d). Causative for these altered flow dynamics was an early postoperative occlusion of the right iliac leg.

The use of B-mode ultrasound enables rapid conclusions regarding hematomas (- Fig. 1e) or lymphoceles in the region of access vessels. On detection of a large hematoma or pulsation, the possibility of active bleeding or false aneurysm must be considered (- Fig. 1f, g). Not only the access vessel itself but also smaller

Gefässchirurgie 2019-24 (Suppl 1):S32-S39 https://doi.org/10.1007/s00772-018-0490-9

(c) The Author(s) 2018

W. Schierling · I. Göcze · H. Apfelbeck · K. Oikonomou · P. M. Kasprzak · K. Pfister

\section{Bedside ultrasound after aortic surgery. Rapid detection of vascular and organ complications}

\section{Abstract}

Background. Early complications after aortic surgery, such as bleeding, vessel occlusion, and organ ischemia require quick and targeted diagnostics to reduce the morbidity and mortality. Ultrasound can be used for quick bedside diagnosis of vascular and organ complications.

Objective. The possibilities of color duplex and contrast-enhanced ultrasound for the detection of vascular and organ complications after aortic surgery are presented.

Results. Vascular access complications, such as acute vessel occlusion, stenosis, dissection, bleeding, hematoma, and false aneurysms can be detected by color duplex ultrasound. The differentiation between hematoma and active bleeding is possible with contrast-enhanced ultrasound. Ultrasound contrast imaging enables the evaluation of hemodynamically relevant dissections and intraluminal thrombi. Furthermore, contrastenhanced ultrasound enables the differential diagnostics of acute kidney failure and a differentiation between complete or partial organ ischemia.

Conclusion. The use of bedside ultrasound for quick detection of early complications after aortic surgery enables optimization of the perioperative management of complications. Further diagnostic and therapeutic interventions can be used in a targeted manner, if necessary. Unnecessary exposure to nephrotoxic radiopaque agents and $\mathrm{X}$-rays and the risks involved in transportation of critically ill patients can therefore be avoided.

Keywords

Vascular diseases - Early complications . Bedside diagnostics - Color duplex ultrasound (CDU) · Contrast enhanced ultrasound (CEUS)

\section{Bettseitiger Ultraschall nach Aorteneingriffen. Schnelle Diagnostik bei Gefäß- und Organkomplikationen}

\section{Zusammenfassung}

Hintergrund. Frühkomplikationen nach Aorteneingriffen wie Blutung, Gefäßverschluss oder Organischämie erfordern eine rasche und zielführende Diagnostik, um Morbidität und Mortalität zu senken. Der bettseitige Ultraschall kann zur schnellen Diagnostik bei Gefäß- und Organkomplikationen eingesetzt werden.

Fragestellung. Es werden die Möglichkeiten der Farbduplex- und Kontrastmittelsonographie nach Aorteneingriffen zur Diagnostik bei Gefäß- und Organkomplikationen dargestellt. Ergebnisse. Gefäßzugangskomplikation wie akuter Verschluss, Stenose, Dissektion, Blutung, Hämatom oder Aneurysma spurium lassen sich mittels Farbduplexsonographie diagnostizieren. Die Unterscheidung zwischen Hämatom und aktiver Blutung ist mittels Kontrastmittelsonographie möglich. Die Relevanz von Dissektionen oder intraluminalen Thromben kann durch die Ultraschallkontrastdarstellung eingeschätzt werden. Die Kontrastmittelsonographie ermöglicht ferner die Differenzialdiagnostik des akuten Nierenversagens sowie eine Unterscheidung zwischen kompletter und partieller Organischämie.

Diskussion. Der Einsatz des bettseitigen Ultraschalls zur schnellen Diagnostik bei Frühkomplikationen nach Aorteneingriffen ermöglicht eine Optimierung des perioperativen Komplikationsmanagements und damit die zielgerichtete Einleitung weiterer diagnostischer und therapeutischer Maßnahmen, wenn erforderlich. Eine unnötige, nephrotoxische Kontrastmittelund Strahlenexposition sowie das Risiko des Transports von kritisch kranken Patienten können so vermieden werden.

\section{Schlüsselwörter}

Vaskuläre Erkrankungen · Frühkomplikationen - Bettseitge Diagnostik . Farbduplexsonographie (FKDS) · Kontrastmittelsonographie (CEUS) 

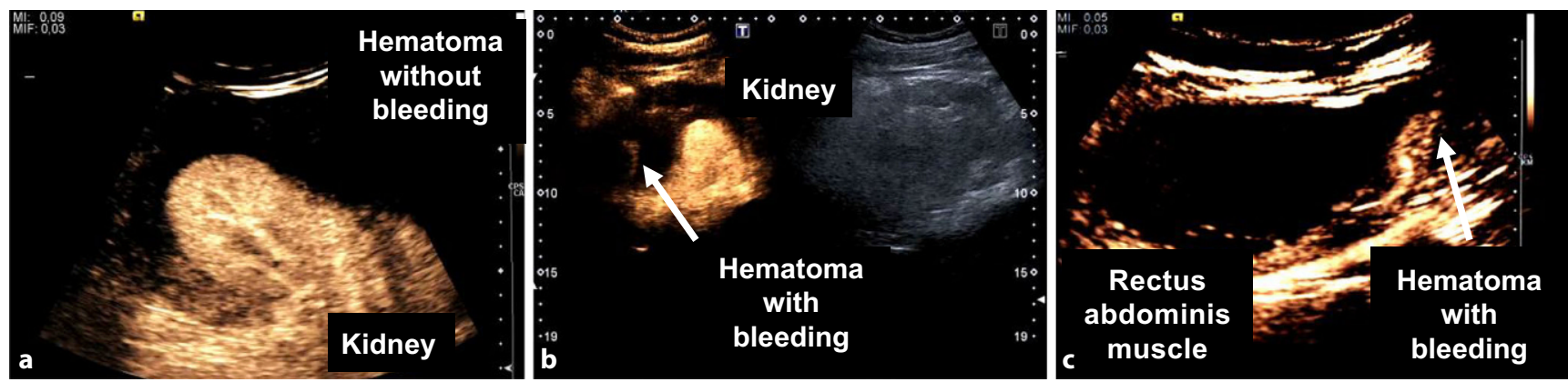

Fig. 2 \ Hematoma and active bleeding in contrast-enhanced ultrasound. a Retroperitoneal hematoma around the kidney with slight organ compression but without contrast agent effusion. $b$ Detection of contrast agent effusion and thus active bleeding in the region of the kidney.c Contrast agent effusion and thus active bleeding in a rectal sheath hematoma. White arrows indicate contrast agent exit/active bleeding
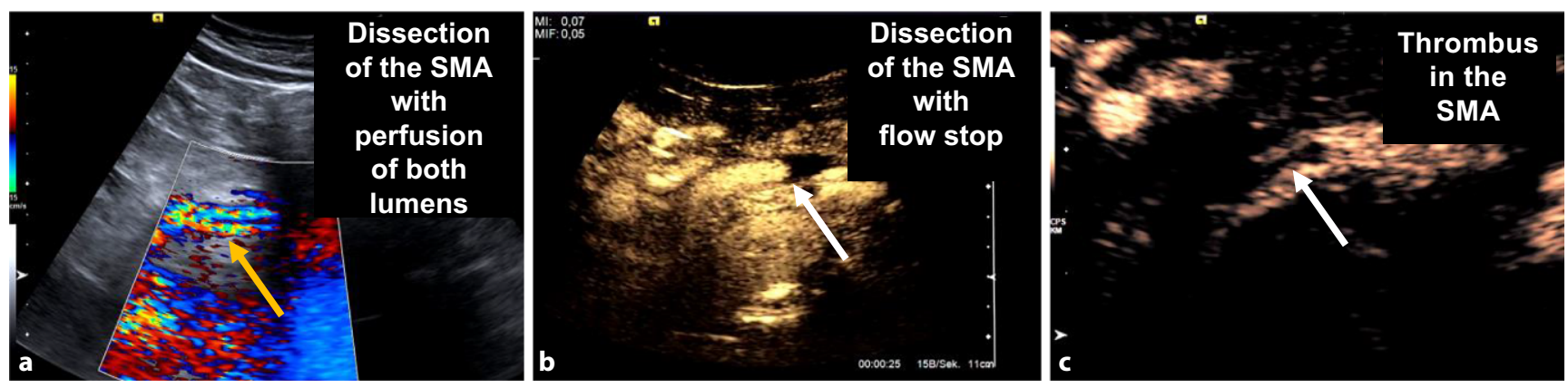

Fig. $3 \Delta$ Dissection and thrombus in the superior mesenteric artery (SMA). a Detection of a dissection membrane in the SMA with perfusion of both lumens (dissection marked with a yellow arrow). $\mathbf{b}$ Detection of contrast agent and therefore flow stop in the SMA resulting from dissection (flow stop marked with a white arrow). c Thrombus detected in a stent graft in the SMA using contrast-enhanced ultrasound (thrombus marked with a whitearrow)

branches may be affected ( $\bullet$ Fig. 1f). Typical for a false aneurysm is detection of to-and-fro flow in the aneurysm neck (• Fig. 1g). To-and-fro flow may be absent in the aneurysm sack due to circulating currents. Depending on the size of the aneurysm and configuration of the neck, compression or an intervention, such as ultrasound-guided thrombin injection or surgery should be discussed.

\section{Bleeding}

In the presence of decreased hemoglobin to a level requiring transfusion and a confirmed retroperitoneal or spontaneous rectal sheath hematoma, the question of active bleeding must be addressed. Perforation of a kidney by the wires is a typical endovascular complication. Contrastenhanced ultrasound allows differentiation between a hematoma ( $\bullet$ Fig. $\mathbf{2 b}$ : retroperitoneal hematoma around the kidney with slight organ compression) and active bleeding ( $\bullet$ Fig. 2 b: retroperitoneal hematoma with active bleeding from the kidney and 0 Fig. $2 \mathrm{c}$ : rectal sheath hematoma with active bleeding. The active bleeding is visualized as flow of contrast agent into the hematoma). In the first instance, conservative treatment is possible; the other two cases require hemostasis (usually interventional).

\section{Dissection and thromboses}

The hemodynamic relevance of dissection membranes or a true lumen collapse in patients with aortic dissection is often difficult to estimate in two-phase examinations such as CTA. Despite continuous imaging, color duplex ultrasound also cannot always enable adequate evaluation of the hemodynamic relevance ( $\bullet$ Fig. 3a; dissection of the superior mesenteric artery [SMA] with perfusion of both lumens and a visible dissection membrane). Contrast-enhanced ultrasound is more likely to be able to detect a flow stop (here portrayed using the example of the SMA, - Fig. 3b), which may result in the indication for emer- gency treatment. Thrombi in the region of the stent graft around which blood continues to flow can be demasked using contrast-enhanced ultrasound ( $\bullet$ Fig. 3c: thrombosis in the stent graft of the SMA. Therapeutic anticoagulation was initiated and the course of the thrombus monitored using contrast-enhanced ultrasound).

\section{Organ complications}

The differential diagnoses of acute kidney failure are of paramount importance, since prerenal kidney failure can be treated using volume therapy and by correction of hypotension and anemia; however, should acute kidney failure occur as a result of stent occlusion or a stent thrombosis, the foremost consideration is immediate revascularization for organ preservation. In contrast-enhanced ultrasound, SonoVue ${ }^{\circledR}$ floods vessels of the entire kidney homogeneously and simultaneously with its arrival in the liver/spleen ( $\mathbf{F i g}$.4a). In cases of acute 
renal ischemia, the kidney remains almost completely black, whereas the liver appears unchanged (• Fig. 4b). Colorcoded portrayal of the time course of contrast agent influx can aid evaluation (parametric imaging; - Fig. 4c: green regular influx; - Fig. 4b: blue significantly delayed contrast agent influx in acute ischemia; - Fig. $4 \mathbf{d}$ from [12]).

\section{》) Parametric imaging can ease evaluation}

If the contrast agent enters the renal medulla normally but not the renal cortex, an acute cortical necrosis, such as in shock, hemorrhage or sepsis, may be present ( $\bullet$ Fig. 4e). Segmental renal infarctions appear as black areas in a kidney with otherwise normal temporal perfusion dynamics (• Fig. 4f). In principle, kidney infarctions can also be visualized in color duplex ( $\mathbf{0} \mathbf{F i g} . \mathbf{4 g}$ ) and B-mode ultrasound; however, demonstration of missing vascularization in a kidney segment with color duplex ultrasound is significantly more difficult in obese and tachypneic patients with pain, and due to the Doppler artefact. In the early phase of the infarction, B-mode ultrasound still reveals normal findings. The low echo demarcation of the infarction zone (- Fig. 4h) is only visible hours later. Where doubt exists, the rapid and much more easily interpreted approach of contrast-enhanced ultrasound should be applied. Contrastenhanced ultrasound is also able to distinguish between normally perfused sections of the intestine and bowel ischemia (- Fig. 4i-j); however, contrastenhanced ultrasound is currently not the preferred method for detection of intestinal ischemia and endoscopy or CTA is used in this scenario.

- Fig. 5 summarizes the recommended diagnostic algorithm with the corresponding diagnostic possibilities of the individual modalities in patients with early complications after aortic interventions. First in line are always B-mode and color duplex ultrasound. If these methods enable a conclusive diagnosis, no further diagnostic procedures are necessary. Where the diagnosis remains unclear, contrast-enhanced ultrasound is the next step. Should it still not be possible to reach a diagnosis, further diagnostic measures are indicated. An exception to this strategy is endoscopy, which should be used early on in cases where intestinal ischemia is suspected; however, it must be borne in mind that the gas insufflation required for endoscopy places severe limitations on the possibilities of subsequent abdominal ultrasound.

\section{Discussion}

Aortic interventions carry a risk for various vessel, organ, and systemic complications [6]. Knowledge of the specific complications associated with the different operative procedures is thus of vital importance. Particularly during the perioperative phase in the ICU, quick and targeted decisions must be made to reduce the perioperative morbidity and therefore also the mortality of these interventions [10].

The value of bedside ultrasound as a noninvasive, cost-effective, radiationfree diagnostic option has also been shown for other clinical intensive care scenarios, e. g., after liver transplantation [8]. Highly important for these patients is the rapid diagnosis of stenoses, false aneurysms, thromboses, and dissections in the hepatic artery. Particularly contrast-enhanced ultrasound significantly improves visualization, while simultaneously enabling evaluation of perfusion in the liver parenchyma [3, 8]. A comparison between the diagnostic accuracy of contrast-enhanced ultrasound and that of a native CT examination in patients with kidney failure revealed correct characterization of liver, kidney, and intestinal pathologies in $96 \%, 89 \%$, and $100 \%$ of cases for contrast-enhanced ultrasound versus $0 \%, 7 \%$, and $18 \%$ for native $\mathrm{CT}$, respectively [13]. The diagnostic accuracy of contrast-enhanced ultrasound for diagnosing splenic artery complications after acute pancreatitis is given as $42 \%$, leading to its description as a safe and effective method for increasing diagnostic certainty [1].

Color duplex ultrasound is the standard diagnostic method for detecting false aneurysms. Characteristic criteria are detection of circulating blood flow in a formation next to the artery and detection of an aneurysm neck with the typical to-and-fro flow (to-and-fro sign) [7]. For blue toe syndrome, a frequent clinical manifestation of microembolisms, ultrasound has been described as the firstchoice diagnostic procedure, enabling detection of the source of the embolism in over $90 \%$ of patients [11]. In their 2012 study dedicated to diagnosis of vascular lesions in arteries of the lower extremities, Gabriel et al. [4] observed a diagnostic agreement between color duplex ultrasound and angiography in $94.6 \%$ of cases. Based on these results, color duplex ultrasound is to be viewed as being of equal value to angiography and CTA for vascular diagnostics of lower extremity arteries.

\section{》) Further targeted diagnostic procedures can be initiated}

After aortic interventions, many questions related to vascular access complications, including hematomas, active and peripheral bleeding, venous thromboses in the legs or organ ischemia, can be answered with B-mode, color duplex, and contrast-enhanced ultrasound in the ICU. Where necessary, further targeted diagnostic or therapeutic measures can then be initiated.

This is of particular importance for the differential diagnoses of acute kidney failure, since it is vital to distinguish between prerenal and intrarenal kidney failure. The risk of contrast agent-induced nephropathy with acute kidney failure is as high as $6.7 \%$ after EVAR [10]. Since average contrast agent volumes for infrarenal aortic stent graft implantation of $50-100 \mathrm{ml}$ have been described [10], renewed administration of iodine-based contrast agent for early postoperative CTA can further increase the risk of contrast agent-induced kidney failure. In this scenario, contrast-enhanced ultrasound is significantly better suited to diagnosis of organ infarction than B-mode [16] or color duplex ultrasound [5]. In two studies from 2006 and 2017, a suspected diagnosis of organ ischemia 

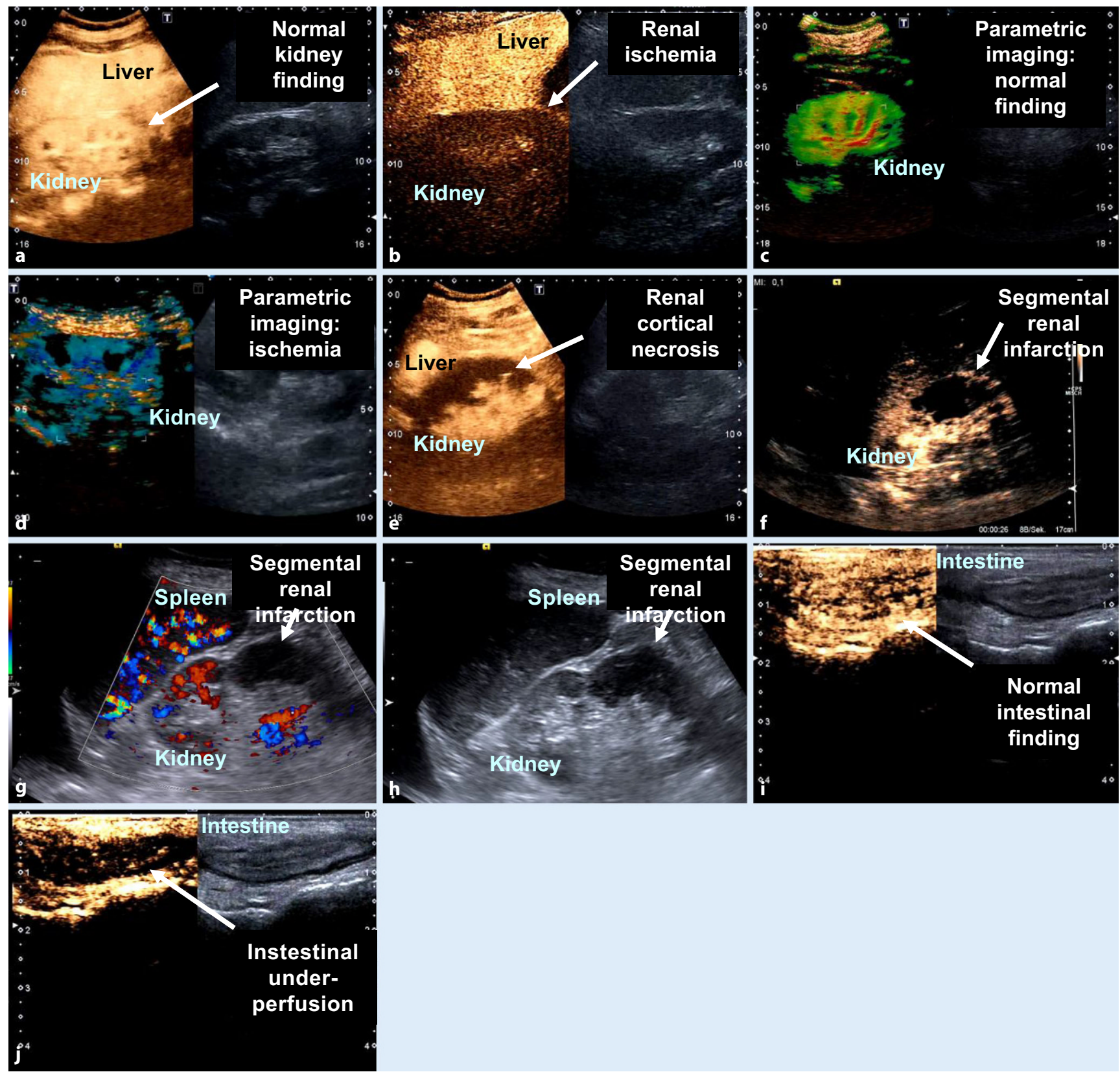

Fig. 4 ム Organ complications (ischemia, necrosis, infarction). a Contrast-enhanced ultrasound with simultaneous influx of contrast agent into liver and kidney, without absence of perfusion. b Unchanged contrast agent influx in the region of the liver but complete absence of perfusion in the area of the kidneys.c, $d$ Parametric imaging of the kidneys for color-coded representation of contrast agent influx in relation to time. green normal influx, blue significantly delayed influx in a patient with acute renal ischemia (source d: Pfister et al. [12]). e Acute renal cortex necrosis with contrast agent influx into the renal medulla only, the cortex remains black. $\mathbf{f}-\mathbf{h}$ Segmental renal infarction. Appearance in contrast-enhanced ultrasound (f), color duplex ultrasound (g), B-mode ultrasound (h). i, j Contrast-enhanced ultrasound showing intestinal segments with normal perfusion and bowel ischemia

could be made in $25 \%$ of patients using B-mode ultrasound [16], organ ischemia could be diagnosed by color duplex ultrasound in 28\% [5] and organ ischemia could be clearly demonstrated by contrast-enhanced ultrasound in $83 \%$ with the remaining $17 \%$ of findings stated to be consistent with organ ischemia
[16]. A differentiation between renal infarction and cortical ischemia was possible, which was not possible with color duplex ultrasound [5]. Moreover, contrast-enhanced ultrasound could also distinguish between cystic and solid kidney pathologies and classify the cysts according to the Bosniak system [5].
In patients with aortic dissection, two or more phase CTA does not always permit adequate evaluation of whether a hemodynamically relevant true-lumen collapse with subsequent organ underperfusion is present; however, continuous observation with contrast-enhanced ultrasound enables imaging of both the 


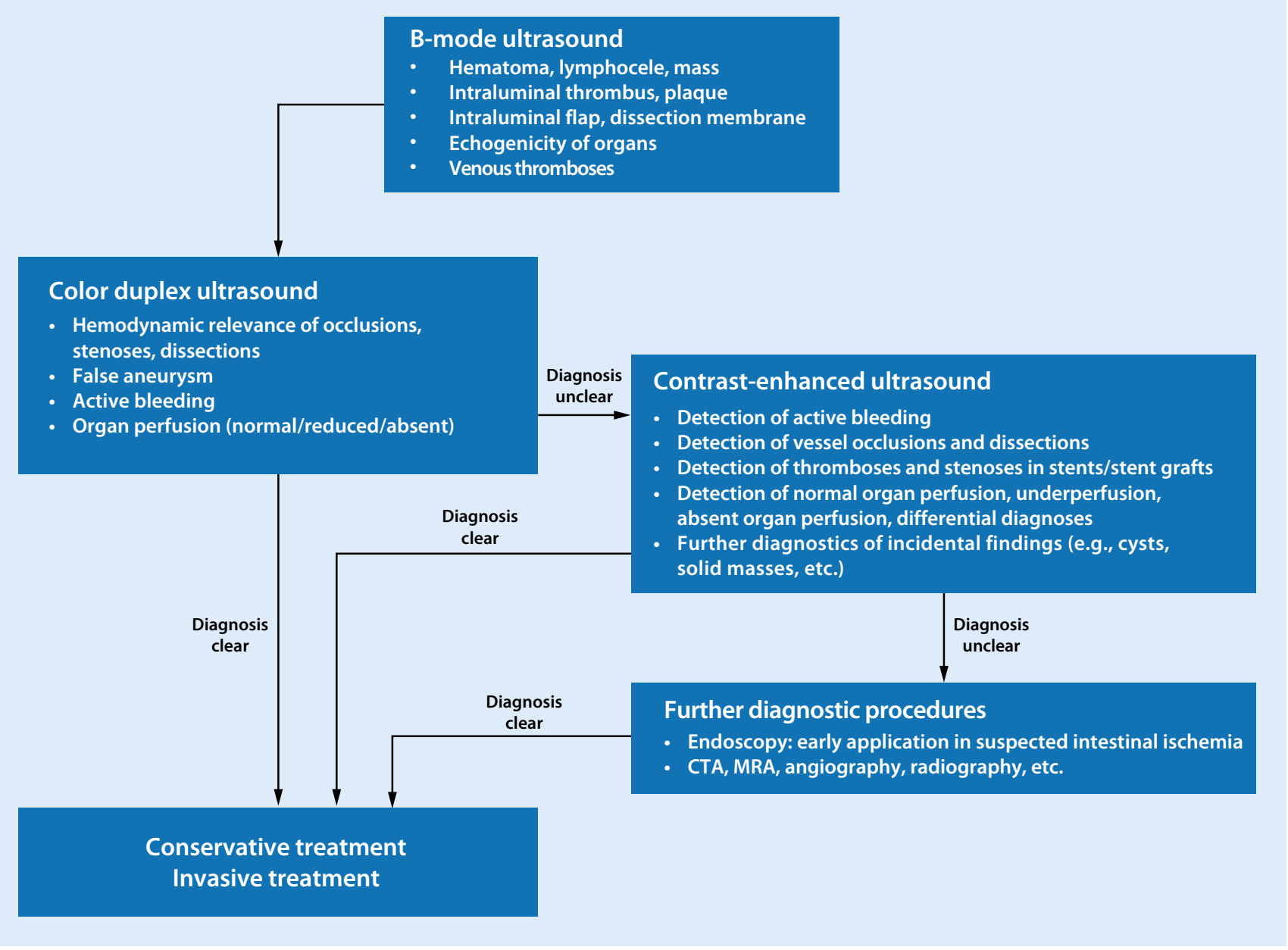

Fig. $5 \Delta$ Diagnostic algorithm for early complications after aortic procedures, including the corresponding diagnostic possibilities of the different individual modalities. CTA computed tomography angiography, MRA magnetic resonance angiography

true and the false lumen, as well as evaluation of organ perfusion. A $3 \mathrm{C}$ recommendation (evidence level 3, recommendation grade C) for evaluation of dissection of the aorta and its primary branches by contrast-enhanced ultrasound is contained in the current EFSUMB guidelines from 2017 [15].

The highest evidence level (1a) and the highest grade of recommendation (A) for vascular contrast agent-enhanced ultrasound remain unchanged for detection and classification of endoleaks during follow-up after endovascular aortic repair [15]. This is generally not of central importance for management of perioperative complications and only relevant after endovascular repair of a ruptured aneurysm. Suspected diagnoses that are currently hardly applicable to evaluation by ultrasound, e.g., acute cerebral ischemia or cerebral hemorrhage and also fulminant pulmonary artery embolisms, continue to require rapid CTA or MRI diagnostics.

In summary, bedside ultrasound after aortic interventions serves to optimize perioperative complications management and thus targeted use of further diagnostic and therapeutic measures. Unnecessary exposure to contrast agent or radiation can be avoided, as can the risk of transporting critically ill patients.

\section{Practical conclusion}

- Early complications after aortic interventions are vascular access complications, bleeding, and organ and systemic complications.

- Rapid and targeted diagnostic procedures are necessary to reduce perioperative morbidity and mortality of these interventions.
- Color duplex and contrast-enhanced ultrasound enable rapid bedside diagnosis of vessel and organ complications after aortic interventions as well as an estimation of the hemodynamic relevance of an aortic dissection.

- The differentiation between hematoma and active bleeding as well as between acute kidney failure and complete or partial organ ischemia is possible with ultrasound contrast imaging.

- Where necessary, further diagnostic and therapeutic measures can be initiated in a targeted manner, and unnecessary exposure to contrast agents and radiation as well as the risk of transporting critically ill patients can be avoided. 


\section{Corresponding address}

PD Dr. W. Schierling
Abteilung für Gefäßchirurgie,
Universitätsklinikum
Regensburg
Franz-Josef-Strauß-Allee 11,
93053 Regensburg, Germany
wilma.schierling@ukr.de

\section{Compliance with ethical guidelines}

Conflict of interest. W. Schierling received travelling expenses from von Bracco Imaging Deutschland $\mathrm{GmbH}$. K. Pfister received travelling expenses and advisor fees from Bracco Imaging Deutschland $\mathrm{GmbH}$. I. Göcze, H. Apfelbeck, K. Oikonomou and P.M. Kasprzak declare that they have no competing interests.

This article does not contain any studies with human participants or animals performed by any of the authors.

The supplement containing this article is not sponsored by industry.

Open Access. This article is distributed under the terms of the Creative Commons Attribution 4.0 International License (http://creativecommons.org/licenses/by/ 4.0/), which permits unrestricted use, distribution, and reproduction in any medium, provided you give appropriate credit to the original author(s) and the source, provide a link to the Creative Commons license, and indicate if changes were made.

\section{References}

1. CaiDM,ParajulySS, Ling WWetal(2014)Diagnostic value of contrast enhanced ultrasound for splenic artery complications following acute pancreatitis. World J Gastroenterol 20:1088-1094

2. Fattori R, Cao P, De Rango P et al (2013) Interdisciplinary expert consensus document on management of type B aortic dissection. J Am Coll Cardiol 61:1661-1678

3. Fontanilla T, Noblejas A, Cortes C et al (2013) Contrast-enhanced ultrasound of liver lesions related to arterial thrombosis in adult liver transplantation. JClin Ultrasound 41:493-500

4. Gabriel M, Pawlaczyk K, Szajkowski R et al (2012) The use of duplex ultrasound arterial mapping (DUAM) and preoperative diagnostics in patients with atherosclerotic ischaemia of lower extremities. Pol Przegl Chir 84:276-284

5. Girometti R, Stocca T, Serena E et al (2017) Impact of contrast-enhanced ultrasound in patients with renal function impairment. World J Radiol 9:10-16

6. Katzen BT, Maclean AA (2006) Complications of endovascular repair of abdominal aortic aneurysms: a review. Cardiovasc Intervent Radiol 29:935-946

7. Lenartova M, Tak T (2003) latrogenic pseudoaneurysm of femoral artery: case report and literature review. Clin Med Res 1:243-247

8. Ma L, Chen K, Lu Q et al (2016) Case report of hepatic artery dissection secondary to hepatic artery pseudoaneurysm after living donor liver transplantation. BMC Gastroenterol 16:44

9. Maldonado TS, Rockman CB, Riles $E$ et al (2004) Ischemic complications after endovascular abdominal aortic aneurysm repair. J Vasc Surg 40:703-709 (discussion 709-710)

10. Maleux G, Koolen M, Heye S (2009) Complications after endovascular aneurysm repair. Semin Intervent Radiol 26:3-9

11. Pawlaczyk K, Gabriel M, Strzelecka-Weklar DA et al (2017) The usefulness of duplex Doppler ultrasound in the angiological and dermatological diagnosis of patients with blue toe syndrome. Postepy Dermatol Alergol 34:478-484

12. Pfister K, Kasprzak PM, Apfelbeck $\mathrm{H}$ et al (2015) Contrast-enhanced ultrasound in vascular medicine. Gefasschirurgie 20:465-476 (German)

13. Sawhney S, Wilson SR (2017) Can ultrasound with contrast enhancement replace nonenhanced computed tomography scans in patients with contraindication to computed tomography contrast agents? Ultrasound Q 33:125-132

14. Schmitz-Rixen T, Steffen M, Grundmann R (2018) Treatment of abdominal aortic aneurysms (AAA) 2016. Registry report from the German Institute of VascularHealthcare Research (DIGG) of the German Society for Vascular Surgery and Vascular Medicin (DGG). Gefasschirurgie 23:174-184 (German)

15. Sidhu PS, Cantisani V, Dietrich CF et al (2018) The EFSUMB guidelines and recommendations for the clinical practice of contrast-enhanced ultrasound (CEUS) in non-hepatic applications: update 2017 (long version). Ultraschall Med 39:e2-e44

16. Von Herbay A, Schick D, Horger M et al (2006) Diagnose von Organinfarkten und Nekrosen in Milz, Niere, Leber und Pankreas mit dem Ultraschallkontrastmittel SonoVue im Vergleich zur Computertomographie. Ultraschall Med. https://doi.org/10.1055/s-2006-953923 (German. Kongressbeitrag) 